\title{
Vibration Response Characteristics and Application of Existing Railway Subgrade
}

\author{
Junyun Zhang $\mathbb{D}^{D}$, Zhuoling He $\mathbb{D}^{D}$, Siyuan Chen $\mathbb{D}^{D}$, and Le Zhang \\ School of Civil Engineering, Southwest Jiaotong University, Chengdu 610031, China \\ Correspondence should be addressed to Junyun Zhang; zjywxfbb@swjtu.edu.cn
}

Received 31 March 2021; Accepted 18 May 2021; Published 28 May 2021

Academic Editor: Gang Fan

Copyright ( 92021 Junyun Zhang et al. This is an open access article distributed under the Creative Commons Attribution License, which permits unrestricted use, distribution, and reproduction in any medium, provided the original work is properly cited.

\begin{abstract}
The existing conventional methods of subgrade disease assessment are not suitable for the existing lines. There are many research studies on the vibration response and attenuation law of the railway subgrade, but few research studies focus on the vibration response and attenuation law caused by the weak subgrade. In this study, vibration response tests were carried out at different positions and depths of the subgrade before and after reinforcement improvement. The results show that vibration response near the ballast is obvious, and it attenuates with the increase of the horizontal distance from the rail; the vibration acceleration response of the subgrade after reinforcement changes greatly; the vibration response curve of the reinforced section is spindle shaped, and the vertical vibration acceleration response attenuates obviously at the depth of $6.5 \mathrm{~m}$, only about $10 \%$ to $30 \%$ of the surface; the vibration acceleration of the subgrade with reinforcement at the depth of $4.5 \mathrm{~m}$ attenuates to $60 \%$ of the surface; the vibration acceleration of the subgrade without reinforcement at the depth of $4.5 \mathrm{~m}$ attenuates to $50 \%-60 \%$ of the surface.
\end{abstract}

\section{Introduction}

At present, the conventional methods for evaluating subgrade diseases mainly include the stiff-plate bearing test $[1,2]$, cone penetration test $[3,4]$, dynamic penetration test [5-8], and ground-penetrating radar [9-14]. Among them, the stiff-plate bearing test and the penetration test could affect the normal operation of the train, and the test point is single, which cannot represent the subgrade state of the section. The ground-penetrating radar could determine the structural layers of the subgrade quickly and soil layers such as ballast bags, but it cannot quantitatively analyze the physical and mechanical indexes of the subgrade. These disease detections for existing line have limitations, not applicable to disease detection of existing lines.

Researchers have carried out a lot of theoretical analysis, numerical simulation test, indoor model test, and field test on vibration response characteristics and attenuation law of the railway subgrade [15-24]. In the early study of the subgrade vibration response, scholars considered the influence of thickness [5], grouping form [25], train speed [26], and properties of soil [27] on subgrade vibration response characteristics and attenuation law. Previous research usually focused on indoor model test and numerical simulation. But as the most direct method for subgrade vibration response characteristics, field tests conducted in China [28, 29], France [30], Germany [31], and UK [32] provided an important basis for the study of subgrade vibration response characteristics. However, there are few field test studies on the vibration response and attenuation law of the diseased subgrade, and the characteristics of the vibration response of the diseased subgrade for a railway line are not definite at present.

Based on Baoji-Zhongwei Railway improvement project, the monitoring results of vibration response difference between the weak subgrade and improved subgrade are compared. And the acceleration in the maximum value, mean value, and effective value are discussed to research the attenuation law of the weak subgrade and improved subgrade. In addition, the selection of monitoring point location is analyzed. The comparison before and after the reinforcement may provide reference for the detection method of the weak subgrade. 


\section{General Situation of Test Site}

Baoji-Zhongwei Railway, built in the 1990s, is a single-line multipurpose railway, as shown in Figure 1. The research site is located in section $\mathrm{K} 329-\mathrm{K} 331,20 \mathrm{~km}$ away from the Guyuan City. The diseased subgrade lies among farmland, and water content in loess at a certain depth of the surface is high due to irrigation. The subgrade shows soft plastic or flow plastic shape, leading to subgrade settlement under the action of train dynamic load. The monitoring section is a typical northwest seasonal frozen region in China, freezing in winter and thawing in summer. As the surrounding farmland is irrigated, the maximum freezing depth is $1.4 \mathrm{~m}-3 \mathrm{~m}$.

\section{Principle}

The subgrade has a certain plasticity. The measured displacement is lagging (Figure 2), and the measured vibration value is affected by many factors. Therefore, the displacement is not suitable for vibration test and analysis. In most of the subgrade vibration response monitoring, the monitoring target train is fast and the frequency is high, and the vibration acceleration is often used as the detection index. Considering the on-site monitoring results and engineering practice, the vibration acceleration is taken as the detection index in this research.

The relationship between vibration acceleration and subgrade stiffness is explained by theoretical derivation of the vibration response of the subgrade surface under moving load, as shown in the following equation:

$$
(\lambda+G) \nabla(\nabla \cdot \vec{u})+G \nabla^{2} \vec{u}+\vec{X}=\rho \frac{\partial^{2} \vec{u}}{\partial t^{2}},
$$

Where $\vec{u}=\vec{u}(\vec{x}, t)=(u(x, y, z, t), v(x, y, z, t), w(x, y, z$, $t))$ is the displacement of viscoelastic half-space; $\vec{X}=\vec{X}(\vec{x}$, $t)=\left(X_{x}(x, y, z, t), X_{y}(x, y, z, t), X_{z}(x, y, z, t)\right)$ is the body force of viscoelastic half-space; $\lambda$ and $G$ are the Lamé parameters of viscoelastic half-space; $\rho$ is the density of viscoelastic halfspace; $\nabla$ is the Hamilton operator; and $\nabla^{2}$ is the Laplace operator.

At present, viscoelastic half-space is widely used to simulate subgrade. The governing equation of the ideal model of viscoelastic half-space expressed is as follows.

For the basic governing equations, there are many ways to solve them. At present, the commonly used methods are the green function method and direct integral change method [33].

According to the geometric equation and physical equation of viscoelastic dynamics, Fourier transform is carried out with respect to the spatial variables $x$ and $y$, as shown in the following equation:

$$
\begin{aligned}
& \sigma_{Z Z}=\left[(\lambda+2 G) \frac{\partial^{2}}{\partial z^{2}}-\lambda\left(k_{1}^{2}+k_{2}^{2}\right)\right] \Phi-2 i G k_{2} \frac{\partial \psi_{1}}{\partial z}+2 i G k_{1} \frac{\partial \psi_{2}}{\partial z} \\
& \tau_{Z X}=G\left[2 i k_{1} \frac{\partial \Phi}{\partial z}+k_{1} k_{2} \Psi_{1}-\left(k_{1}^{2}+\frac{\partial^{2}}{\partial z^{2}}\right) \psi_{2}\right], \\
& \tau_{Z X}=G\left[2 i k_{1} \frac{\partial \Phi}{\partial z}+k_{1} k_{2} \Psi_{1}-\left(k_{1}^{2}+\frac{\partial^{2}}{\partial z^{2}}\right) \psi_{2}\right],
\end{aligned}
$$

where $\Phi$ is the scalar function; $\Psi_{1}$ and $\psi_{2}$ are vector functions; $\lambda$ and $G$ are the Lamé constants of viscoelastic half-space; $\rho$ is the density of viscoelastic half-space; and $k_{1}$ and $k_{2}$ are the wave numbers along the directions of $x$ and $y$.

Stress boundary condition of viscoelastic questions is imported, as shown in the following equation:

$$
\begin{aligned}
z & =0, \\
\sigma_{z z} & =-F, \\
\tau_{z x} & =0, \\
\tau_{z y} & =0 .
\end{aligned}
$$

Considering the above formula, the acceleration can be obtained as

$$
\begin{aligned}
a= & -\frac{P c^{2}}{4 \pi^{2} G} \int_{-\infty}^{+\infty} \int_{-\infty}^{+\infty} \frac{k_{1}^{2}}{\Delta}\left[B_{p}\left(k_{1}^{2}+k_{2}^{2}+B_{s}^{2}\right) e^{-B_{p} z}\right. \\
& -2 B_{p}\left(k_{1}^{2}+k_{2}^{2}\right) e^{-B_{s} z} e^{i\left(k_{1} x+k_{2} y-k_{1} c t\right) \mathrm{d} k_{1} \mathrm{~d} k_{2}},
\end{aligned}
$$

where $P$ is the value of load, $\delta(\cdot)$ is the load action function, $f(t)$ is the load function which changes over time, $B_{p, s}^{2}=k_{1}^{2}+k_{2}^{2}-k_{p, s}^{2}, k_{p, s}=\omega / c_{p, s}, \omega$ is the vibrational frequency, and $k_{1}$ and $k_{2}$ are the wave numbers along the directions of $x$ and $y$.

It can be seen from the above formulas that the vibration acceleration of the subgrade can reflect the stiffness characteristics of the subgrade to a certain extent. The stiffness properties of the subgrade before and after treatment are obviously different. Hence, it is reasonable that vibration acceleration is used to reflect the stiffness properties of the subgrade in this research.

\section{Monitoring Scheme}

4.1. Vibration Response Monitoring Equipment. An 891-2 vibration pickup developed by the Institute of Engineering Mechanics, CEA, was used in this test, as shown in Figure 3. Moreover, an amplifier and an acquisition instrument were adopted for monitoring, and the connection among the instruments is shown in Figure 4. The vibration pickup was connected to the amplifier to amplify the collected vibration response signal by a certain multiple. And then it was connected to the data acquisition instrument. The data acquisition instrument was connected with the computer to directly analyze and sort out the test signal.

4.2. Reinforcement Scheme. Sections K329+530 and $\mathrm{K} 330+990$ were reinforced by rotary jet grouting piles from December 3, 2016, to December 15, 2016, as shown in Figure 5. Rotary jet grouting piles were used to reinforce this section of subgrade. The distance between the rotary jet grouting piles was $2 \mathrm{~m}$, arranged crosswise.

4.3. Arrangement of Measuring Points. Three representative sections were selected for vibration monitoring in this monitoring, $\mathrm{K} 329+530, \mathrm{~K} 330+990$, and $\mathrm{K} 331+315$, to comprehensively analyze the vibration response 

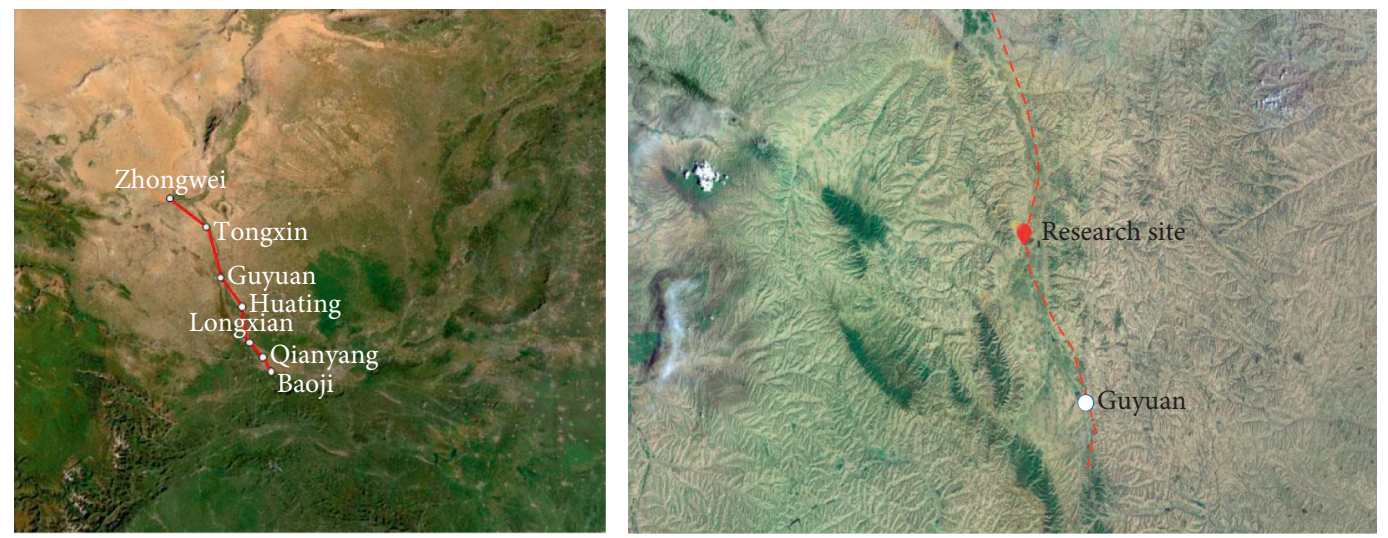

FIgure 1: The location of research site.

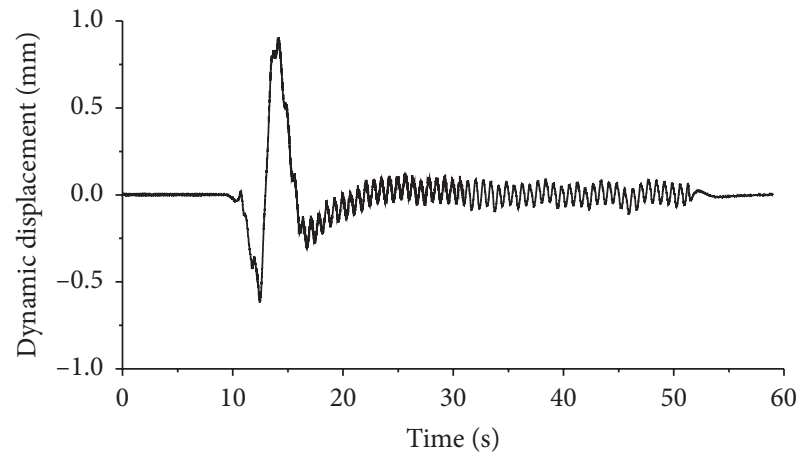

FIgURE 2: Time history diagram of dynamic displacement.

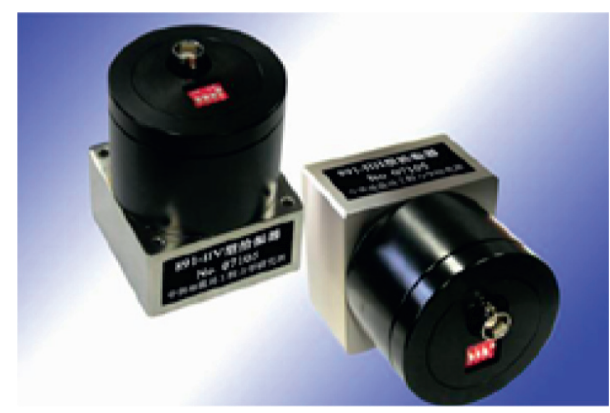

FIGURE 3: 891-2 vibration pickup.

characteristics of existing railway subgrade. $\mathrm{K} 331+315$ is weak subgrade, and the other two are improved subgrades. And the vibration acceleration of the subgrade adjacent to ballast, foot of subgrade, and subgrade underneath the foundation were monitored, respectively. Three directions are specified, of which the $X$ direction is parallel to the rail direction (longitudinal), the $Y$ direction is perpendicular to the rail direction (transverse), and the $Z$ direction is vertical, as shown in Figure 6(a).

Measuring point $\mathrm{C} 1$ and measuring point $\mathrm{C} 2$ were arranged in section $\mathrm{K} 329+530$, to monitor the response characteristics of subgrade vibration at different locations. In this test, two measuring points were set on the surface

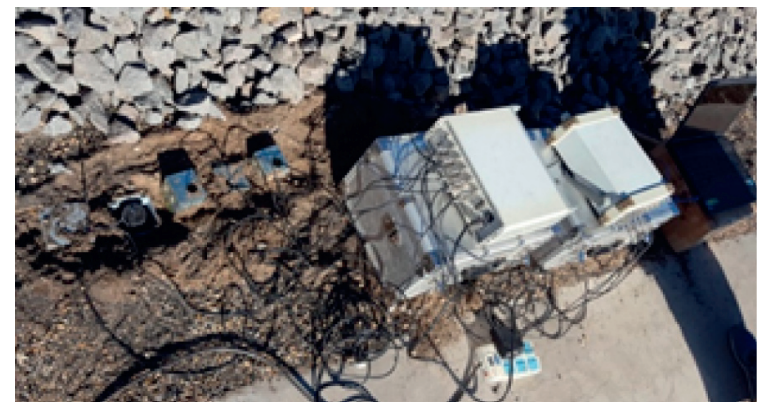

Figure 4: Connection among the instruments.

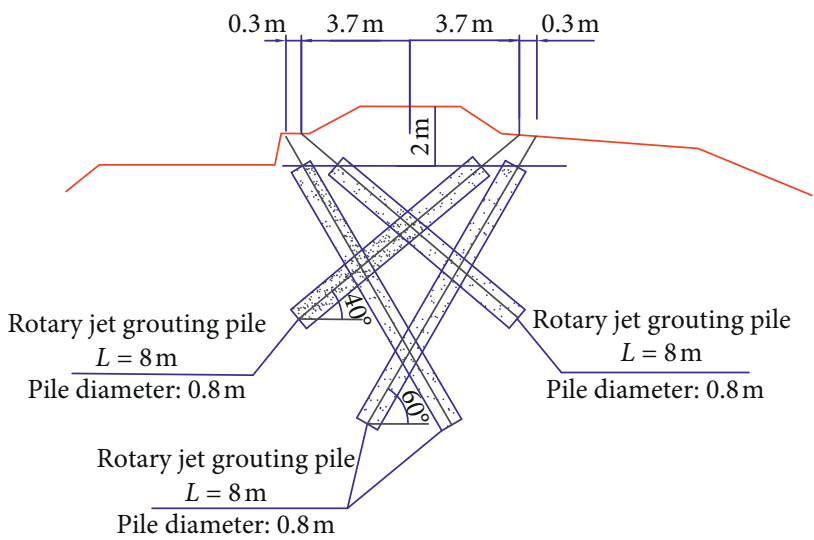

FIGURE 5: Plane layout of existing railway subgrade strengthened by inclined rotary jet grouting pile.

perpendicular to the direction of embankment. Measuring point $\mathrm{C} 1$ was set at the ballast and measuring point $\mathrm{C} 2$ was set at the bottom of embankment, as shown in Figure 6(b).

In order to research the propagation and attenuation law of the vibration response along soil depth before and after subgrade reinforcement treatment as well as the seasonal variation, measuring points were arranged in sections $\mathrm{K} 330+990$ and $\mathrm{K} 331+315$. Considering the communication optical cable along the railway, the measuring points 


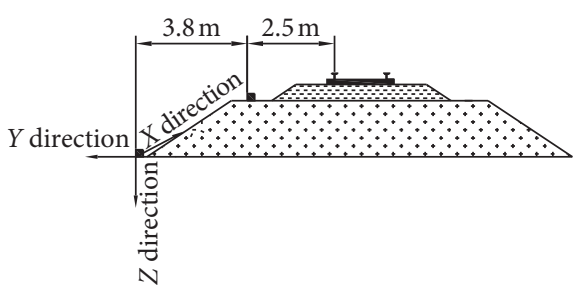

(a)

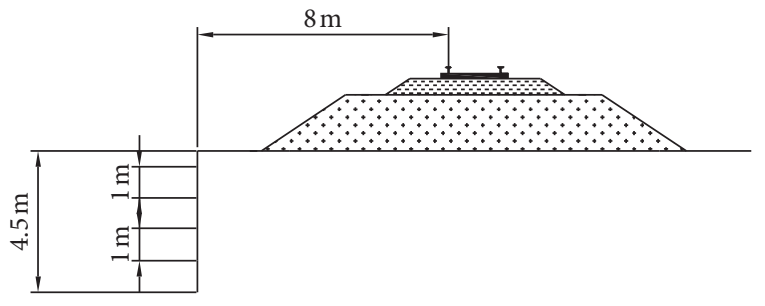

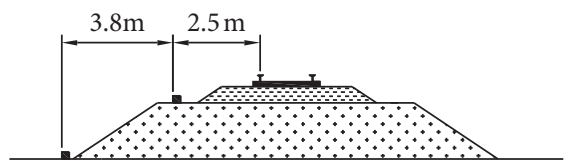

(b)

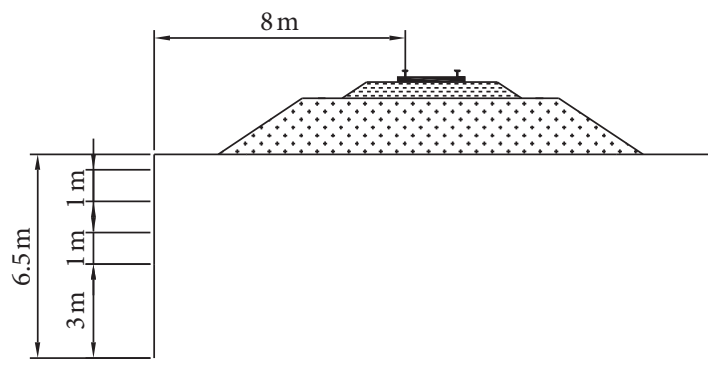

(d)

FIgURE 6: Schematic diagram of the layout of the vibrator pickup. (a) The layout direction of the vibrator. (b) Section K329 + 530. (c) Section K330 + 990. (d) Section K331 + 315 .

were arranged at a distance of $8 \mathrm{~m}$ from the rail horizontal distance. The specific layout depths of $\mathrm{K} 330+990$ section after subgrade reinforcement were $0.5 \mathrm{~m}, 1.5 \mathrm{~m}, 2.5 \mathrm{~m}, 3.5 \mathrm{~m}$, and $6.5 \mathrm{~m}$, respectively, as shown in Figure 6(c). The specific layout depths of section K331 +315 section before subgrade reinforcement treatment were $0.5 \mathrm{~m}, 1.5 \mathrm{~m}, 2.5 \mathrm{~m}, 3.5 \mathrm{~m}$, and $4.5 \mathrm{~m}$, respectively, as shown in Figure 6(d).

\section{Results and Analysis}

5.1. Selection of Vibration Direction and Value. The response of subgrade vibration influenced by train passing is a complex forced composite action. In order to elaborate this response more reasonably, different physical representative values need to be taken for analysis. In this paper, the characteristic values of vibration acceleration are defined as follows: the average value of the absolute maximum acceleration, in which 5 maximum acceleration values and 5 minimum acceleration values are calculated; the effective value while the train passes; and the average value while the train passes. The expression of the three is shown in equations (5)-(7).

$$
\begin{aligned}
\left|a_{i}\right|_{\max }= & \frac{\sum_{j=1}^{N}\left|a_{i}\right|_{\max }}{N} \\
& \cdot(i=X, Y, Z ; j=1,2,3, \ldots, N=10), \\
\left|a_{i}\right|_{\mathrm{val}}= & \frac{1}{N} \sqrt{\sum_{j=1}^{N}\left|a_{i}\right|^{2}} \\
& \cdot(i=X, Y, Z ; j=1,2,3, \ldots, N),
\end{aligned}
$$

$$
\left|a_{i}\right|_{\mathrm{ave}}=\frac{\sum_{j=1}^{N}\left|a_{i}\right|}{N} \quad(i=X, Y, Z ; j=1,2,3, \ldots, N) \text {. }
$$

From Figure 7, it can be seen that among the three directions of vibration acceleration, the largest is vertical vibration acceleration ( $Z$ direction) and the smallest is $Y$ direction. In addition, the mean and the effective values are more obvious than the maximum, and the mean and the effective values in $Z$ direction are more significant than those in other two directions. Therefore, the mean and effective values of vertical vibration acceleration are taken as the indexes to study the attenuation law of vibration acceleration of damaged subgrade.

5.2. Vibration Response along Horizontal Distance of Subgrade. It can be seen from Figures 8 and 9 that before foundation reinforcement, the peak vertical, longitudinal, and transverse vibration accelerations near ballast are $8.45 \mathrm{~mm} / \mathrm{s}^{2}, 14.4 \mathrm{~mm} / \mathrm{s}^{2}$, and $22.3 \mathrm{~mm} / \mathrm{s}^{2}$, respectively, while the peak vertical, longitudinal, and transverse vibration accelerations of the foot of the subgrade are $6.85 \mathrm{~mm} / \mathrm{s}^{2}$, $6.37 \mathrm{~mm} / \mathrm{s}^{2}$, and $3.06 \mathrm{~mm} / \mathrm{s}^{2}$, respectively; the vibration response decreases with the increase of the horizontal distance from rails. The vibration response of $\mathrm{C} 1$ measuring point is more obvious, and it is suitable to study the vibration response characteristics before and after subgrade reinforcement if considering the actual situation.

\subsection{Vibration Response before and after Subgrade Reinforcement}

5.3.1. Time-Domain Curve. Figure 10(a) shows a time history diagram of vibration acceleration at $\mathrm{K} 331+315$ 


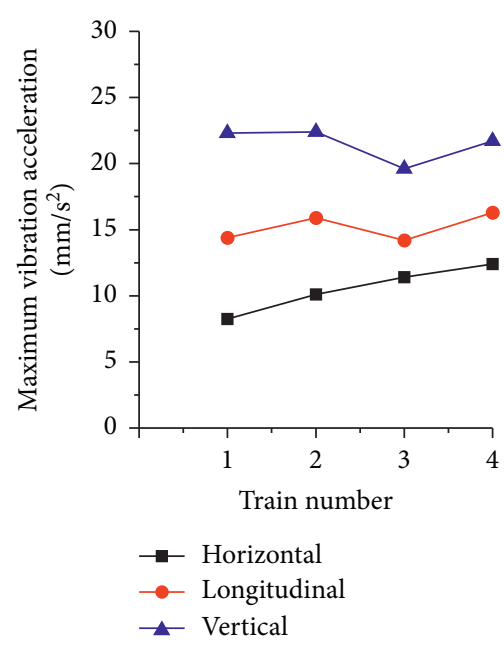

(a)

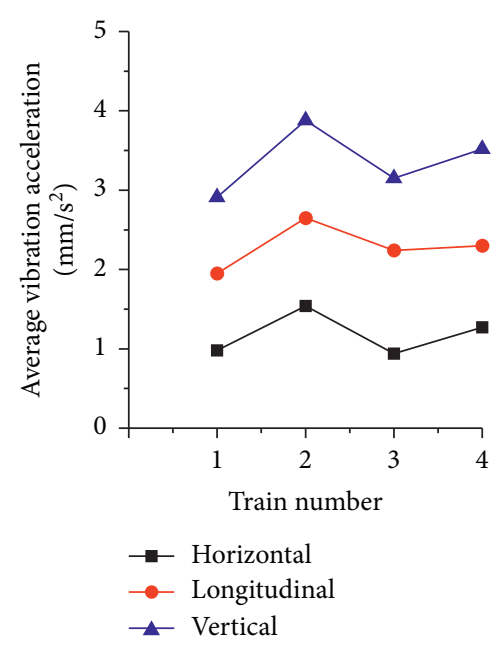

(b)

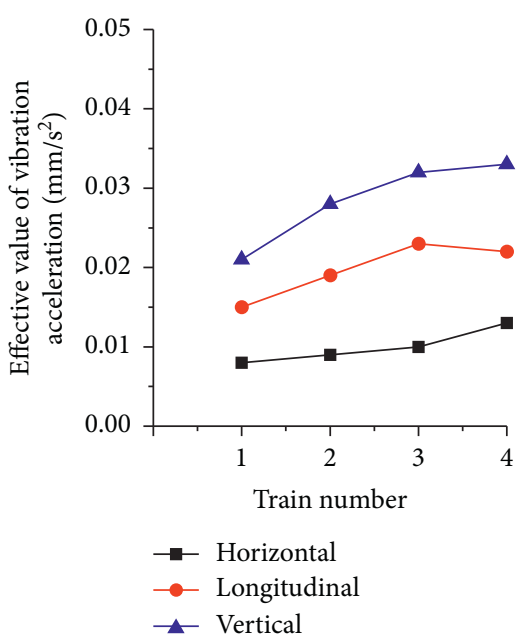

(c)

Figure 7: Vertical vibration acceleration at K329+530 C1 measuring point. (a) Maximum before reinforcement. (b) Average acceleration before reinforcement. (c) Effective value before reinforcement.

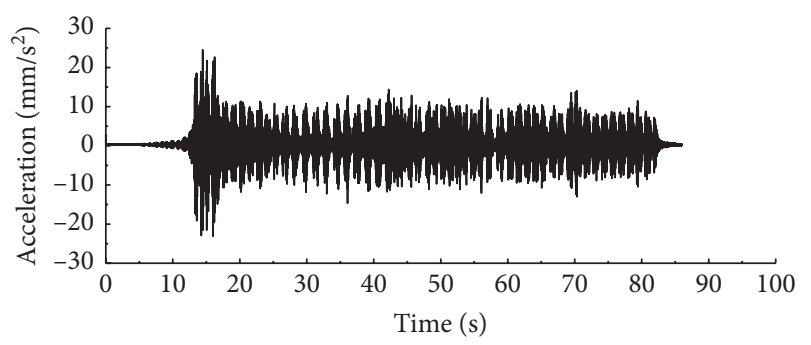

(a)

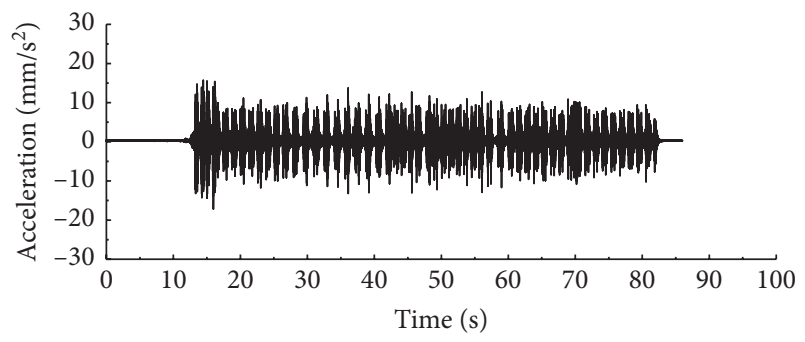

(b)

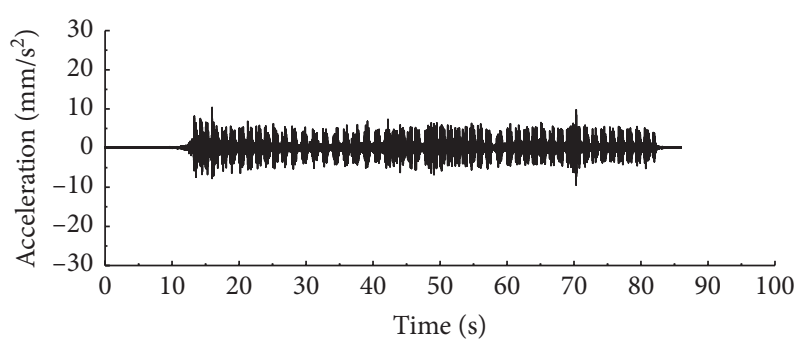

(c)

FIgURE 8: Time-domain curves of vibration acceleration of $\mathrm{C} 1$ measuring point before subgrade reinforcement-truck in different directions: (a) $\mathrm{Z}$ direction. (b) $\mathrm{Y}$ direction. (c) $\mathrm{X}$ direction.

measuring point when a truck passes by. The vibration response at various depths and the vibration acceleration caused by wheel pairs at different depths at the same time can be clearly seen in the diagram. The vibration acceleration response at $0.5 \mathrm{~m}$ away from the surface is greater than that at $1.5-3.5 \mathrm{~m}$, and the vibration acceleration attenuation at $4.5 \mathrm{~m}$ is obvious. Figure $10(\mathrm{~b})$ shows the response time history diagram of subgrade vibration acceleration at $\mathrm{K} 330+990$ measuring point. It can be seen in the diagram that the response of vibration acceleration caused by train passing is consistent from top to bottom. The response time history curve of subgrade vibration acceleration caused by train passing shows periodic variation characteristics with obvious peak and oscillation characteristics, which are excited directly by periodic wheel and axle forces of the train. The peak and valley of the vibration acceleration response at $6.5 \mathrm{~m}$ underground are not obvious, and the time history curve is close to the spindle shape. Refraction and reflection occur when the vibration wave reaches this depth, which leads to nonperiodicity of vibration.

5.3.2. Vibration Attenuation Law. According to the result of vibration direction, the mean and the effective values in $Z$ direction are more significant than those in other two directions. Therefore, the vibration attenuation law of vertical vibration was studied, as seen in Figures 11 and 12. 


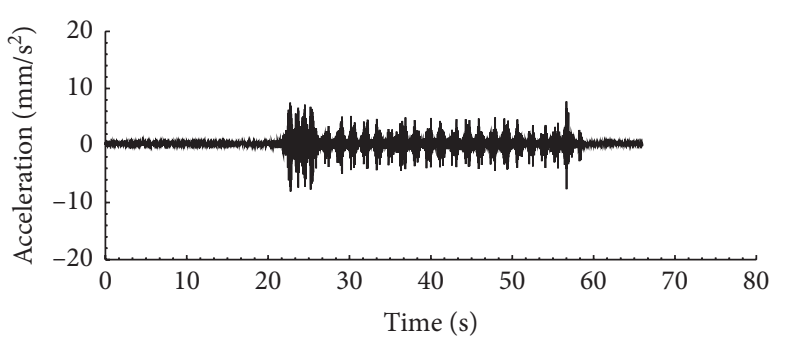

(a)

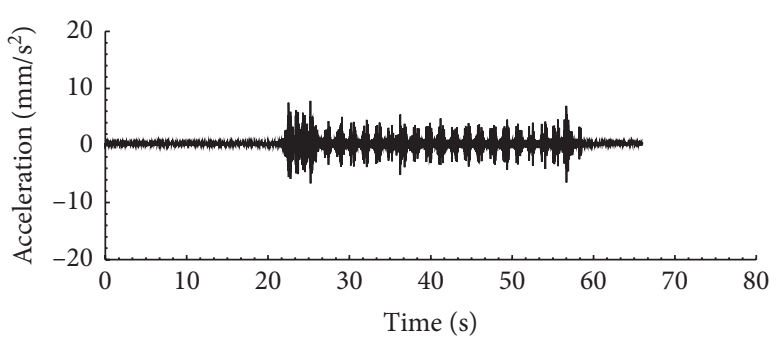

(b)

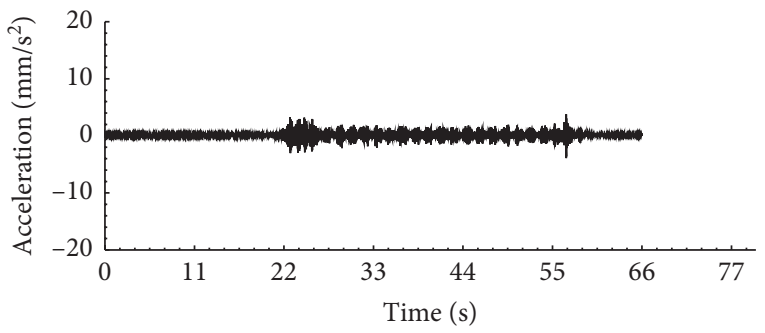

(c)

FIGURE 9: Time-domain curves of vibration acceleration of $\mathrm{C} 2$ measuring point before subgrade reinforcement-truck in different directions: (a) $Z$ direction. (b) $Y$ direction. (c) $X$ direction.

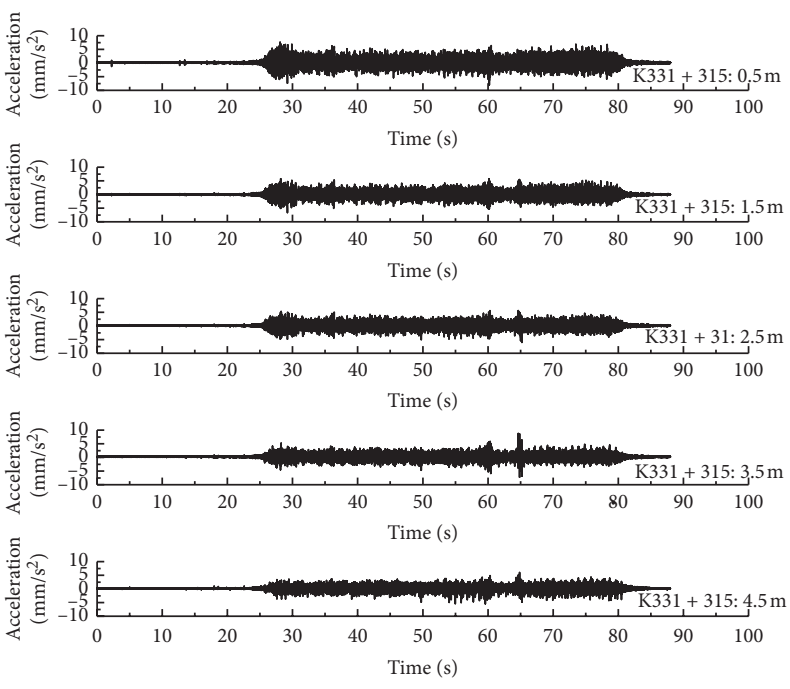

(a)
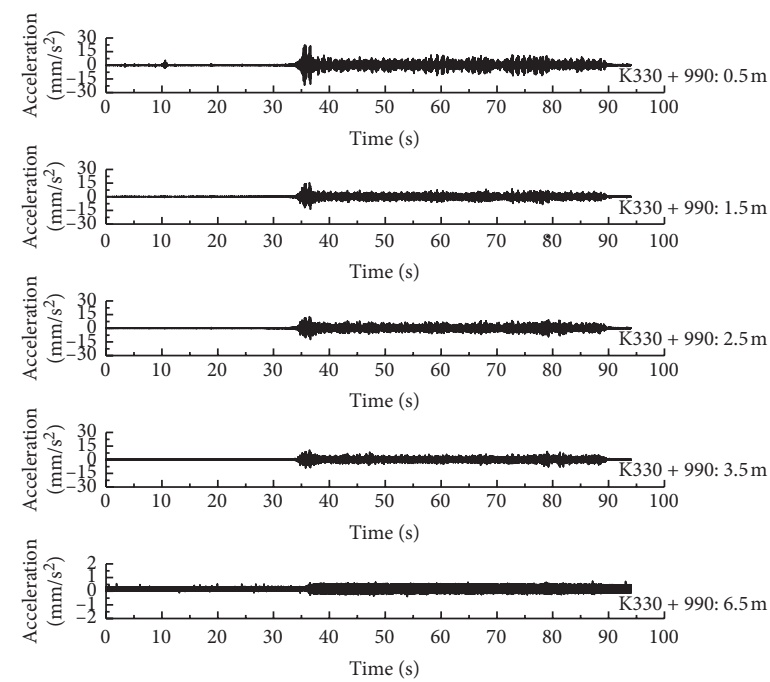

(b)

Figure 10: Time-domain diagram of vertical vibration acceleration. (a) K331 + 315. (b) K330 + 990 .

(1) The average value of vibration acceleration at the $\mathrm{K} 330+990$ subgrade shallow layer $(Z=0.5 \mathrm{~m})$ is $2.45 \mathrm{~mm} / \mathrm{s}^{2}$, while the corresponding average value of vibration acceleration at the subgrade deep layer $(Z=6.5 \mathrm{~m})$ is only $0.15 \mathrm{~mm} / \mathrm{s}^{2}$, which reflects the attenuation process of vibration propagation in soil. Due to the dissipation of vibration energy by soil material damping and geometric damping, the vibration acceleration of soil gradually decreases with the increase of depth.

(2) Maximum of time history curve of soil vibration acceleration corresponds to load-force time history curve, which reflects the loading characteristics of moving loads of trains. Among them, $0.5-4.5 \mathrm{~m}$ has obvious loading characteristics of vibration acceleration time history curve due to its shallow distance to the ground surface, while $6.5 \mathrm{~m}$ has no obvious loading characteristics due to its deep distance to the vibration source.

(3) The vibration response of different measuring points differs greatly, and the vibration response of the reinforcement section is larger than that of the nonreinforcement section as a whole. For K330+990 measuring point, the vibration attenuation is 


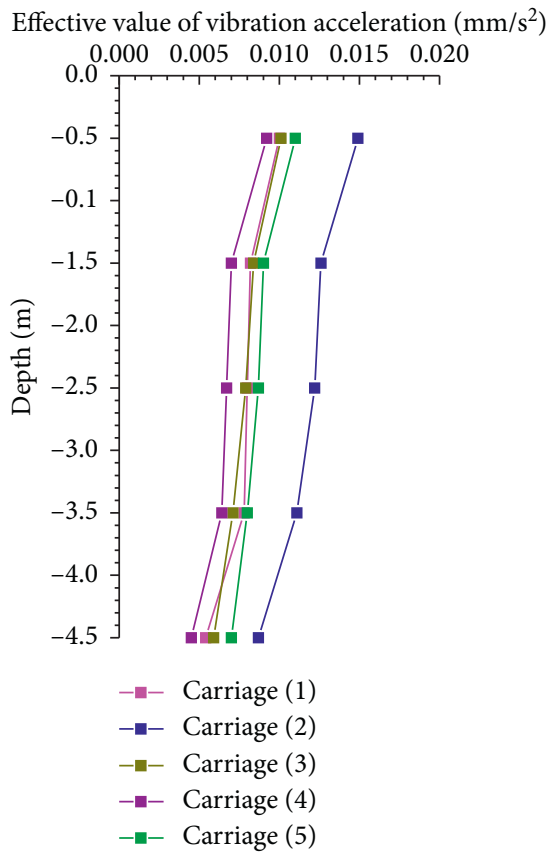

(a)

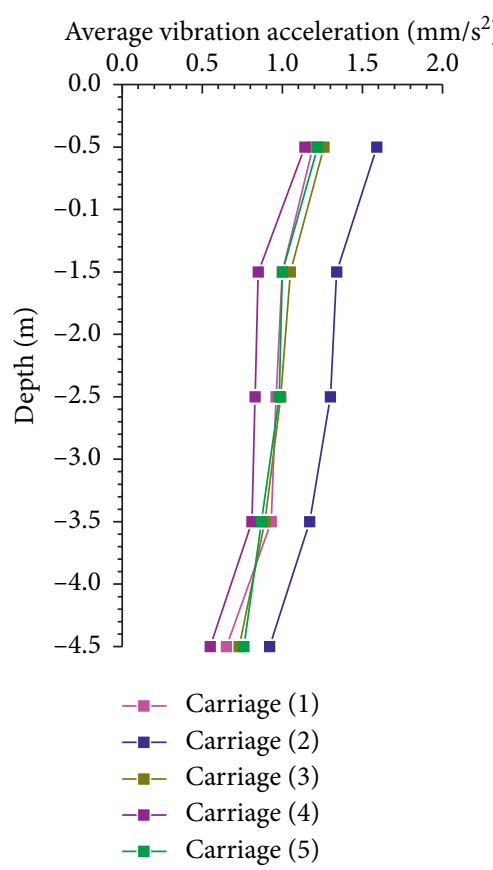

(d)
Effective value of vibration acceleration $\left(\mathrm{mm} / \mathrm{s}^{2}\right)$

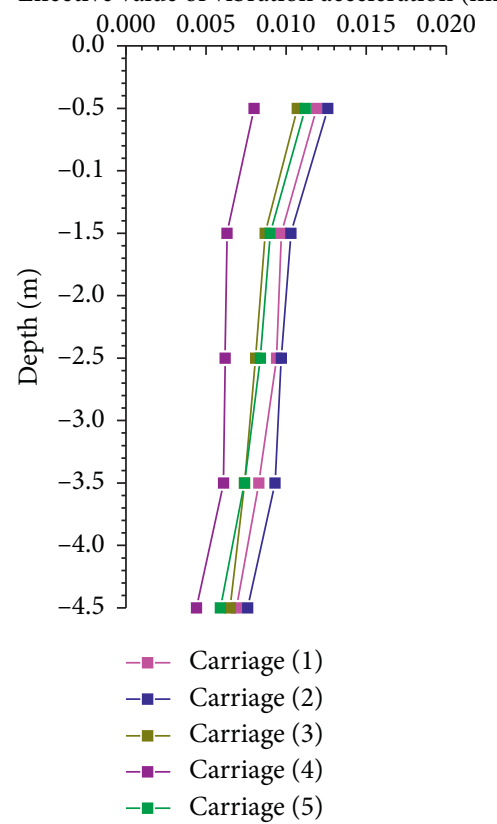

(b)

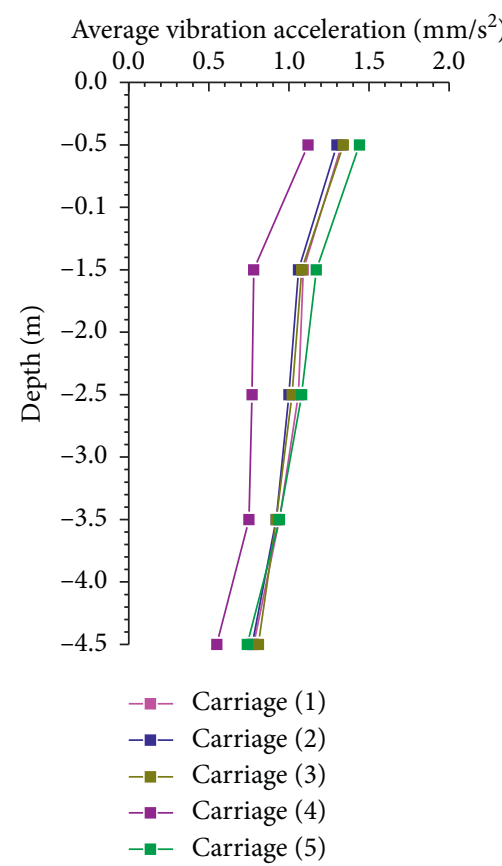

(e)
Effective value of vibration acceleration $\left(\mathrm{mm} / \mathrm{s}^{2}\right)$

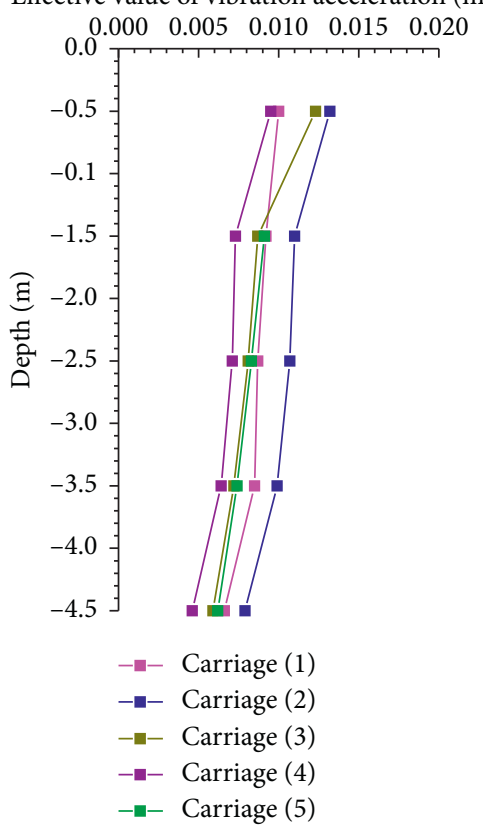

(c)

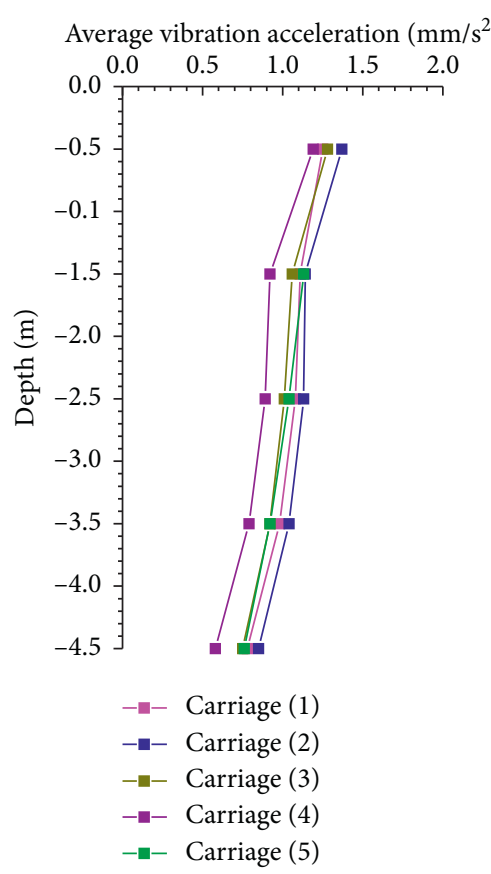

(f)

Figure 11: Effective value and average value of vertical vibration acceleration at K331 + 315 measuring point. (a) Effective value attenuation curve in September 24th. (b) Effective value attenuation curve in October 10th. (c) Effective value attenuation curve in October 24th. (d) Average attenuation curve in September 24th. (e) Average attenuation curve in October 10th. (f) Average attenuation curve in October 24th.

obvious. At $6.5 \mathrm{~m}$ depth, the vibration acceleration attenuates to one tenth of the surface; at K331+315 measuring point, at $4.5 \mathrm{~m}$ depth, the vibration acceleration attenuation is only $50 \%-60 \%$ of the surface.

\section{Discussion}

The results of needle subgrade treatment project and on-site monitoring show that the response of vibration acceleration is obviously different before and after subgrade 


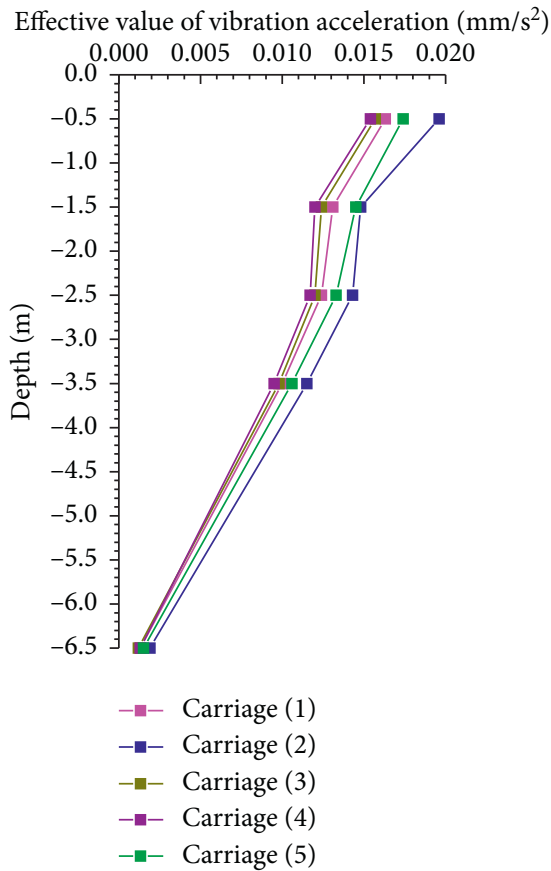

(a)

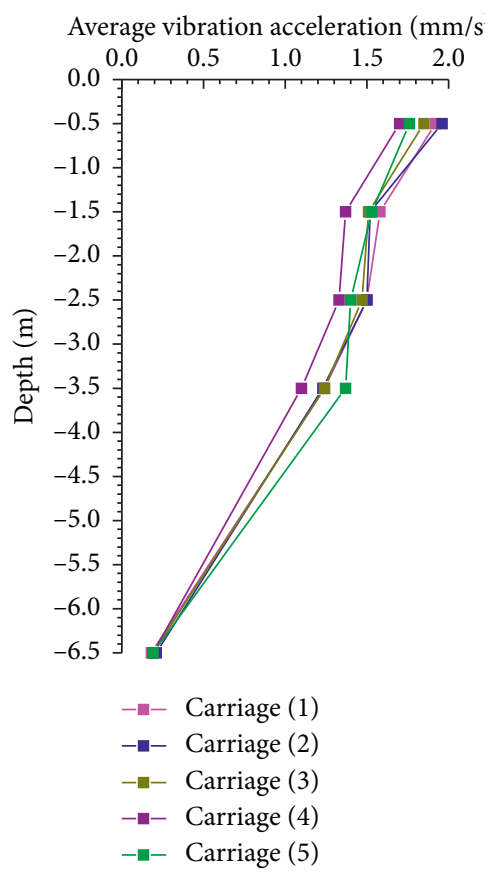

(d)
Effective value of vibration acceleration $\left(\mathrm{mm} / \mathrm{s}^{2}\right)$

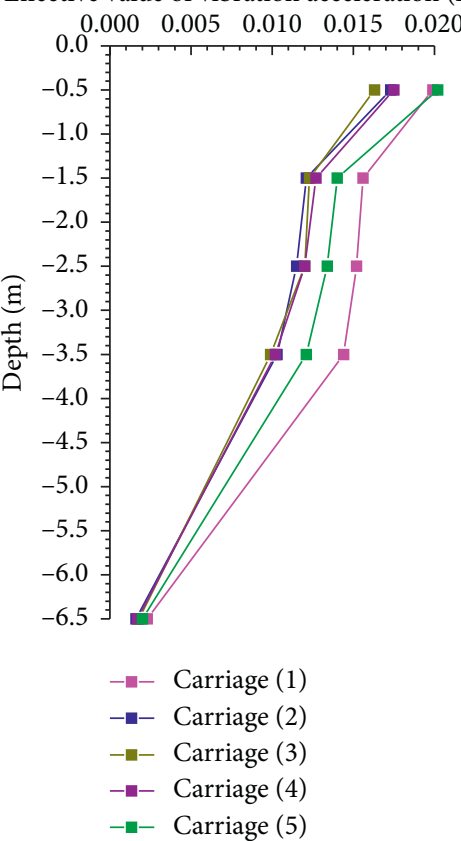

(b)

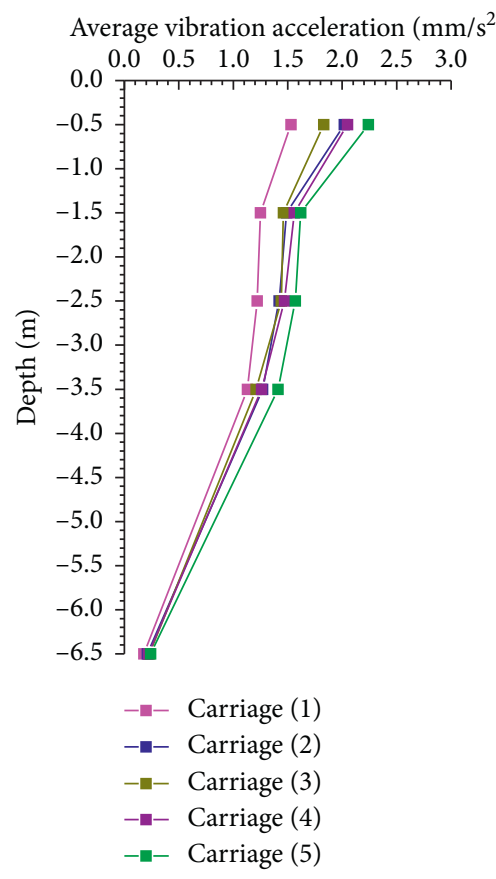

(e)
Effective value of vibration acceleration $\left(\mathrm{mm} / \mathrm{s}^{2}\right)$

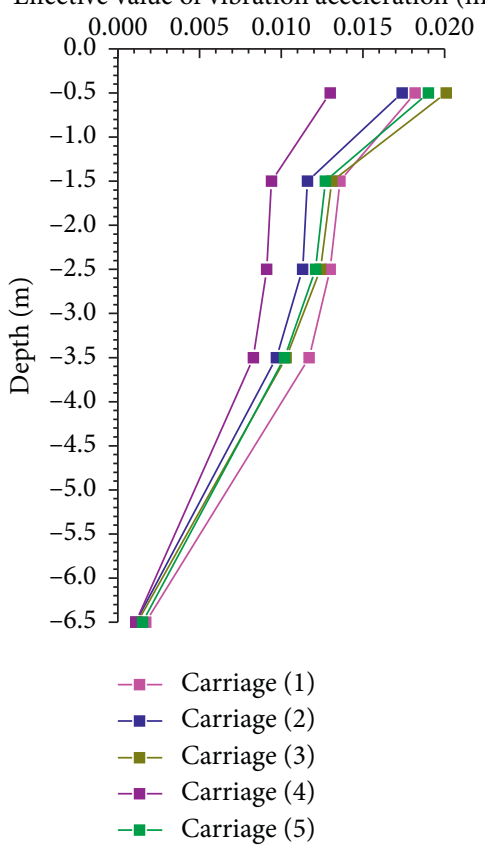

(c)

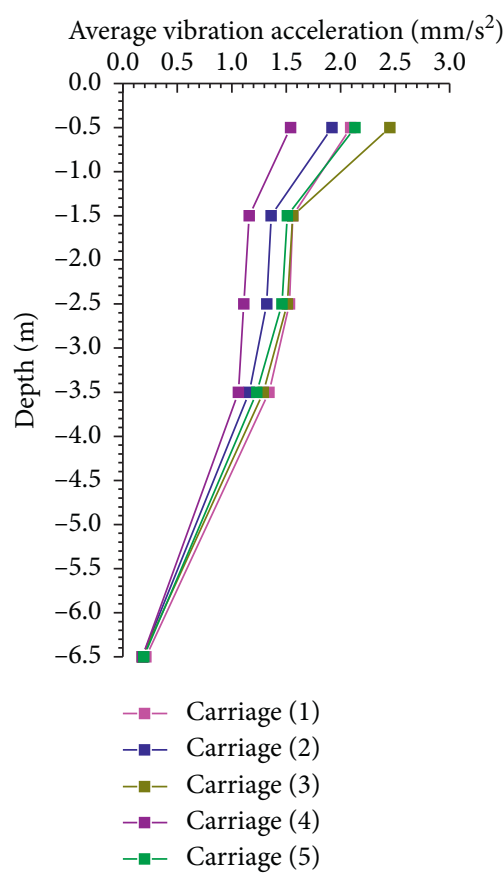

(f)

Figure 12: Effective value and average value of vertical vibration acceleration at K330 +990 measuring point. (a) Effective value attenuation curve in September 23rd. (b) Effective value attenuation curve in October 11th. (c) Effective value attenuation curve in October 22nd. (d) Average attenuation curve in September 23rd. (e) Average attenuation curve in October 11th. (f) Average attenuation curve in October 22nd.

reinforcement. At the same time, the monitoring of the reinforced section and unreinforced diseased section shows that the vibration response of the reinforced section is generally larger than that of the unreinforced section in the same period. Based on the above results, the method of vibration response detection is discussed to detect subgrade diseases.
(1) The vibration response near the ballast is obvious and decreases with the increase of the horizontal distance from the rail. Therefore, the ballast can be taken as the measuring point. Considering the actual field conditions such as the width of ballast rail and whether there is a stone shoulder, this position can be taken as a point from the ballast to the middle of 
the stone shoulder. And the distance is $2.5 \mathrm{~m}$ which is more in line with actual engineering.

(2) Among the three directions of vibration acceleration, the transverse vibration acceleration is the smallest, followed by the longitudinal vibration acceleration, and the vertical vibration acceleration is the largest. The vibration response curve of the reinforced section is spindle shaped, and the vertical vibration acceleration response attenuates obviously at $6.5 \mathrm{~m}$ depth, only about $10 \%$ to $30 \%$ of the surface. The vibration acceleration of the subgrade at $4.5 \mathrm{~m} \mathrm{de}$ creases to more than $60 \%$ of the surface, while that of the unreinforced section attenuates to $50 \%-60 \%$ of the surface at $4.5 \mathrm{~m}$.

\section{Conclusion}

At present, the conventional methods for evaluating subgrade diseases mainly include the stiff-plate bearing test, cone penetration test, dynamic penetration test, and groundpenetrating radar. But these disease detections have limitations for the disease detection of existing line. In this paper, vibration response tests were carried out at different positions and depths of the damaged subgrade of the existing railway before and after reinforcement improvement, and some conclusions are as follows:

(1) The vibration response near the ballast is obvious and decreases with the increase of the horizontal distance from the rail. Considering the actual situation, it is reasonable to take $2.5 \mathrm{~m}$ distance from rail as the measuring point.

(2) The response of vibration acceleration before and after subgrade reinforcement changes significantly.

(3) The vibration acceleration of the reinforced subgrade at $4.5 \mathrm{~m}$ decreases more than $60 \%$ of the surface, while that of the vibration acceleration of the unreinforced section attenuates to only $50 \%-60 \%$ of the surface.

\section{Data Availability}

The test data used to support the findings of this study are included within the article.

\section{Conflicts of Interest}

The authors declare that there are no conflicts of interest regarding the publication of this paper.

\section{Acknowledgments}

This research was supported by the Sichuan Province Science and Technology Support Program (grant nos. 2021YFS0321, 2020YJ0253, and 2020YFSY0060). The authors also gratefully acknowledge Southwest Jiaotong University for support. The authors appreciate all the institutions and individuals that have provided support for this study.

\section{References}

[1] L. Bertulienè, A. Laurinavičius, and A. Vaitkus, "Research and evaluation of methods for determining deformation modulus of a base course of road pavement," The Baltic Journal of Road and Bridge Engineering, vol. 5, no. 2, pp. 110-115, 2010.

[2] L. Bertulienè, A. Laurinavičius, and O. Lapinskiene, "Research of strength measurement methods on subgrade of experimental road pavement," The Baltic Journal of Road and Bridge Engineering, vol. 0 7, no. 3, pp. 228-236, 2012.

[3] G. Q. Wang, "Engineering features and foundation division of rock and soil masses in Hefei city," Chinese Journal of Rock Mechanics and Engineering, vol. 18, no. 6, pp. 694-698, 1999.

[4] G. Q. Wang, W. Xu, D. X. Wu et al., "Characteristics of environmental geology and geological disasters of Anhui province," Chinese Journal of Rock Mechanics and Engineering, vol. 23, no. 1, pp. 164-169, 2004.

[5] M. Brough, A. Stirling, G. Ghataora, and K. Madelin, "Evaluation of railway trackbed and formation: a case study," NDT\&E International, vol. 36, no. 3, pp. 145-156, 2003.

[6] Y. Byun and J. Lee, "Instrumented dynamic cone penetrometer corrected with transferred energy into a cone tip: a laboratory study," Geotechnical Testing Journal, vol. 36, no. 4, pp. 533-542, 2013.

[7] R. Salgado and S. Yoon, "Dynamic cone penetration test (DCPT) for subgrade assessment," Technical Summary, Joint Transportation Research Program, Indiana Department of Transportation and Purdue INDOT Research FHWA/IN/ JTRP-2002/30, West Lafayette, IN, USA, 2003.

[8] Y. H. Byun, H. K. Yoon, Y. S. Kim et al., "Active layer characterization by instrumented dynamic cone penetrometer in Ny-Alesund," Svalbard," Cold Regions Science And Technology, vol. 104-105, pp. 45-53, 2014.

[9] K. M. Hinkel, J. A. Doolittle, J. G. Bockheim et al., "Detection of subsurface permafrost features with ground-penetrating radar," Barrow, Alaska," Permafrost and Periglacial Processes, vol. 12, no. 2, pp. 179-190, 2001.

[10] B. J. Moorman, S. D. Robinson, and M. M. Burgess, "Imaging periglacial conditions with ground-penetrating radar," Permafrost and Periglacial Processes, vol. 14, no. 4, pp. 319-329, 2003.

[11] Y. Z. Ma, Y. S. Zhang, S. Zubrzycki et al., "Hillslope-Scale variability in seasonal frost depth and soil water content investigated by GPR on the southern margin of the sporadic permafrost zone on the Tibetan plateau," Permafrost and Periglacial Processes, vol. 26, no. 4, pp. 321-334, 2015.

[12] A. V. Titov and S. S. Krylov, "Physical and mathematical modeling approaches for GPR investigation of underground ice in the permafrost zone," in Proceedings of the SAGEEP 2015-28th Annual Symposium On the Application Of Geophysics To Engineering And Environmental Problems, Austin, TX, USA, 2015.

[13] J. P. Xiao and L. B. Liu, "Permafrost subgrade condition assessment using extrapolation by deterministic deconvolution on multifrequency GPR data acquired along the QinghaiTibet railway," IEEE Journal of Selected Topics in Applied Earth Observations and Remote Sensing, vol. 9, no. 1, pp. 83-90, 2016.

[14] E. Léger, B. Dafflon, F. Soom et al., "Quantification of Arctic soil and permafrost properties using Ground-Penetrating radar and electrical resistivity tomography datasets," IEEE Journal of Selected Topics in Applied Earth Observations and Remote Sensing, vol. 10, no. 10, pp. 4348-4359, 2017. 
[15] V. V. Krylov, "Generation of ground vibrations by superfast trains," Applied Acoustic, vol. 44, no. 2, pp. 149-164, 1995.

[16] H. Takemiya and X. C. Bian, "Substructure simulation of inhomogeneous track and layered ground dynamic interaction under train passage," Journal of Engineering Mechanics, vol. 131, no. 7, pp. 699-711, 2005.

[17] L. Yang, W. Powrie, and J. A. Priest, "Dynamic stress analysis of a ballasted railway track bed during train passage," Journal of Geotechnical and Geoenvironmental, vol. 135, no. 5, pp. 680-689, 2009.

[18] X. Bian, Y. Chen, and T. Hu, "Numerical simulation of highspeed train induced ground vibrations using 2.5 D finite element approach," Science China Physics, Mechanics \& Astronomy, vol. 51, no. 6, pp. 632-650, 2008.

[19] X. Bian, W. Jin, and H. Jiang, "Ground-borne vibrations due to dynamic loadings from moving trains in subway tunnels," Journal of Zhejiang University-SCIENCE B, vol. 13, no. 11, pp. 870-876, 2012.

[20] H. Mei, W. Leng, R. Nie et al., "Random distribution characteristics of peak dynamic stress on the subgrade surface of heavy-haul railways considering track irregularities," Soil Dynamics and Earthquake Engineering, vol. 116, pp. 205-214, 2019.

[21] Y. Momoya, E. Sekine, and F. Tatsuoka, "Deformation characteristics of railway roadbed and subgrade under moving-wheel load," Soils and Foundations, vol. 45, no. 4, pp. 99-118, 2005.

[22] Z. He, J. Y. Zhang, and T. Sun, "Influence of maximum particle diameter on the mechanical behaviour of Soil-Rock Mixtures," Advances in Civil Engineering, vol. 2020, no. 3, Article ID 8850221, 9 pages, 2020

[23] J. Y. Zhang, Z. L. He, and X. Yu, "Three-dimensional finite element modeling of soft rock tunnel with large section: a case study," Frontiers in Physics, vol. 8, Article ID 577787, 2020.

[24] Z. L. He and J. Y. Zhang, "Compaction quality inspection method of soil-rock filled embankment based on continuous compaction control technology," Advances in Civil Engineering, vol. 2021, no. 3, Article ID 8894042, 12 pages, 2021.

[25] X. Sheng, C. J. C. Jones, and M. Petyt, "Ground vibration generated by a load moving along a railway track," Journal of Sound and Vibration, vol. 228, no. 1, pp. 129-156, 1999.

[26] G. Lombaert and G. Degrande, "Experimental validation of a numerical prediction model for free field traffic induced vibrations by in situ experiments," Soil Dynamic and Earthquake Engineering, vol. 21, no. 6, pp. 485-497, 2001.

[27] A. M. Kaynia, C. Madshus, and P. Zackrisson, "Ground vibration from high-speed trains: prediction and countermeasure," Journal of Geotechnical and Geoenviromental Engineering, vol. 126, no. 6, pp. 531-537, 2000.

[28] L. Wang, "Vibration characterization of fully-closed high speed railway subgrade through frequency: sweeping test," Soil Dynamics and Earthquake Engineering, vol. 88, pp. 33-44, 2016.

[29] J. Xiao, B. Wang, C. Liu et al., "Influences of subgrade form and ground stiffness on dynamic responses of railway subgrade under train loading: field testing case study," Procedia Engineering, vol. 143, pp. 1185-1192, 2016.

[30] D. P. Connolly, P. A. Costa, G. Kouroussis et al., "Large scale international testing of railway ground vibrations across Europe," Soil Dynamics and Earthquake Engineering, vol. 71, pp. 1-12, 2015.

[31] P. Galvín and J. Domínguez, "Experimental and numerical analyses of vibrations induced by high-speed trains on the
Cordoba -Malaga line," Soil Dynamics and Earthquake Engineering, vol. 29, no. 4, pp. 641-657, 2009.

[32] P. A. Costa, R. Calçada, and A. S. Cardoso, "Track-ground vibrations induced by railway traffic: in-situ measurements and validation of a 2.5 D FEM-BEM model," Soil Dynamics and Earthquake Engineering, vol. 32, no. 1, pp. 111-128, 2012.

[33] H. Zhou, Study On Dynamic Response Of Structures And Ground Subjected To Moving Loads, Zhejiang University, Hangzhou, China, 2005. 